Article

\title{
Coupling TPACK instructional model with computing artificial intelligence techniques to determine technical and vocational education teacher's computer and ICT tools competence
}

\author{
Sezer Kanbul ${ }^{1}$, Idris Adamu ${ }^{2,2 *}$, A.G. Usman ${ }^{3}$, and S. I. Abba ${ }^{4,5^{*}}$ \\ 1 Computer Education and Instructional Technology, Department Near East University Nicosia 99138, Cy- \\ prus, sezer.kanbul@neu.edu.tr, sezerkanbul@gmail.com \\ 2 Computer Education and Instructional Technology, Department Near East University Nicosia 99138, Cy- \\ prus \\ 2 Curriculum \& Instruction Department, Aminu Saleh College of Education PMB 044 Azare Bauchi State \\ Nigeria, idrisadamu2623@gmail.com \\ 3 Department of Analytical Chemistry, Faculty of Pharmacy, Near East University, Nicosia, Turkish Re- \\ public of Northern Cyprus; abdullahigusman@gmail.com \\ 4 Interdisciplinary Research Center for Membrane and Water Security, King Fahd University of Petroleum \\ and Minerals, Dhahran 31261, Saudi Arabia \\ 5 Faculty of Engineering, Department of Civil Engineering, Baze University, Abuja, Nigeria \\ * Correspondence: e-mail@e-mail.com; Tel.: (sani.abba@kfupm.edu.sa)
}

\begin{abstract}
Nowadays, emerging technologies have changed the places of work through computers and ICT tools, which have revolutionized teaching and learning environments in different ways. In spite of the fact that computers as ICT tools have become part and progressively instrument for instructors used in teaching and learning, most educators can't incorporate them into their teaching and learning process, which results in students being ill-equipped or lacking some necessary skills in the world of work, which leads to low performance and poor production. To tackle this issue, it is essential to develop the technical and vocational education and training (TVET) system by determining the quality of TVE. In this paper, the literature concerning the competence required by TVET teachers towards computer-related instructional technology for classroom teaching and learning was examined through the technological pedagogical content knowledge (TPACK) model. Sixty (60) questionnaires were administered to TVE teachers within six technical colleges of education in north-eastern Nigeria. The data was quantitatively analyzed using traditional linear models, namely multilinear regression (MLR) and artificial intelligence (AI) models, namely artificial neural networks (ANN) and adaptive neuro-fuzzy inference systems (ANFIS), which were developed using MATLAB 9.3 (R2019a), while the classical linear MLR model was developed using SPSS software. The results from our classical study indicated that TVE teachers are competent in computer and some instructional technology usage and show a high correlation between competence and teaching experience and a lower correlation between competence and gender. The goodness of fit shows a good fit of the model. Future studies should examine the application of other linear and non-linear AI techniques.
\end{abstract}

Keywords: artificial intelligence, TPACK, teachers, competence, computer, TVE

\section{Introduction}

Globalization piques the need for training teachers of the present and next eras, specifically the establishment of a modern, on a very basic level, culture of teacher's work and the arrangement of competent instructors, which is one of the most vital angles of the concept of instruction modernization. The rapid development of information and communication technologies has enabled the rise of new knowledge and 
skills distinct from those of the previous century. As the world relies more on technology due to the pervasiveness of computers and related technologies and the advanced web, there is a developing need to enable individuals to acquire this pre-requisite knowledge to meet the needed demand [1,4]. The implementation and incorporation of technology has now become a requirement in teaching and learning processes, requiring high levels of epicurean ICT users. The integration of computers to improve instructive learning in this modern period may be a major issue for its integration into teaching and learning. Computer technology has provided teachers with many opportunities to incorporate computers into the teaching and learning processes. For different curricular subjects, computers and other ICT tools substantially accelerate research in teaching and learning. Non-instructional technologies such as record keeping, average communication, and pre-instructional computer technology are also becoming more popular. Materials, instructional content analysis, usage Device use by teachers who are similar is linked to constructivism, collaboration, and investigation as well as a pedagogical shift [1]. According to studies conducted in various developed and information-based countries around the world, computer technology will never be able to replace teachers, and teachers will continue to be the key players in unlocking the true potential of computer technology in education. As a result, teachers must become computer literate and be equipped to use information technology. Being prepared to incorporate and use technology, as well as understanding how technology can help learners to become essential skills in every teacher's certified gamut [1]. A professional competence teacher should establish conditions for the development of new technologies and ideas that can be used to build a complex framework of interrelationships with the world. The VTE programs have a crucial role to play in the social and economic growth and development of every country.

Today's concern is not so much about the worth and importance of VTE, but how to ensure relevance, flexibility, and value in an era of globalization [2]. To provide a quality workforce in the training industry, delivered courses and programs must comply with technological advancement at the manufacturing site. This scenario is improving steadily across disciplines. The best TVET systems are focused on coordinating their performance in order to be comparable to other specialized development areas. The recent shift aims to shift the skeptical views of TVET away from second-class schooling and toward the development of skilled trade individuals. has been successfully utilized in education and learning since the 1960s. The reason behind utilizing computers in this domain is that it incorporates experimental learning, inspiration, improved and upgraded students' accomplishments, genuine research materials, more prominent cooperation, individualization, autonomy from a singular source of data, and around the world understanding [4]. As per the study by [5], it was found that information and communication technologies comprise apparatuses such as smart phones, iPhones, tablets, laptops, individual computerized associates, projectors, and versatile DVD players, which can be utilized by encouraging classroom teachers. As opined by [6], computers and other technologies are essential tools for innovative teaching and play a significant role in the interactions between teachers and students.

As indicated in a study by [7], opined that computer information and communication technologies, information technology, or computer-related technologies, consist of electronic devices that reshape the world in all aspects of human endeavor. It is recognized that information and communication technologies through the use of computers are vital skills for the present generation to meet the global standard and that these skills are necessary for modern education systems around the world. TVET Teacher Training's most important role is to encourage teachers to obtain training to allow them to prepare their students not only for today, but also for tomorrow's modern society and the world of work [8]. Previous studies conducted by [9] [10] clarify the need to integrate techno- 
logically instructive and content learning with the pervasive development of these studies of nature and innovative technologies needed to investigate the development of teacher competence related to computers and other ICT tools. Traditional methods of instruction, according to [11], are beginning to lose viability as instructors are increasingly responsible for teaching. The fruitful utilization of ICT in schools requires an interest in framework as well as progressions in instructors' abilities to coordinate these new devices into teaching and learning. So as to set up methodical help instruments for educators' expert improvement, it is important to show the skills that are required for utilizing ICT in schools and classrooms, which will clear out the poor performance among graduates in the set employment that resulted in teachers' low competence during teaching and learning. Despite many programs and major efforts in different developing countries, there is still a long way to go toward incorporating computer and ICT technology into education.

Despite the support of computers as teaching and learning tools, it has often been found that teachers and schools are generally reluctant to facilitate the use of computers in the curriculum [1]. There are limited empirical literature studies about the technical and vocational education teachers' computers, ICT tool competencies, their background, and information and communication technology profiles, which are mixed with the support they receive from the teachers' training institute on computer-related technologies or ICT competencies. Despite this assertion, a definitive study defining a technical and vocational teacher's computer technology competence has not been attempted. This study contributes to the current novelty literature. Therefore, this study aims to investigate the competence needed by TVE teachers and their demographic backgrounds, as well as some ICT characteristics enshrined in the support, they get from teacher training institutions on ICT. The objective of this study is presented as follows: (i) to investigate the competencies required of technical education teachers in the use of computers and other ICT-technology tools in the classroom. (ii) to investigate competencies needed by vocational teachers toward computer-innovative ICT technology for classroom teaching; (iii) to evaluate whether there is a relationship between technical and vocational teachers' computer technology competency levels with certain demographic backgrounds; and (iv) to employ the artificial intelligence (AI) models in the TVE area.

\subsection{Research Motivation}

The exponential growth of technology and internet connectivity has given rise to a modern world that has had an impact on all aspects of people's lives. The complexities of labor advertising for scholastically discharged youthful graduates, the requirement for social relations between regions, and insufficient social imply, to name a few factors, have increased the risk of youth disengagement from occupations [12]. In spite of exceptionally considerable speculation, the introduction of computers and other ICT apparatuses into the classroom is a larger part of specialized and professional instruction. Instructors are not totally leveraging such instructive advances. Education financial experts in a variety of countries have used ICT to improve instructional performance and make strides in the quality and adequacy of education and learning [13].it may be, such a guess is not being realized. The National Center for Instruction Measurements (NCES) announced that 100 per cent of schools within the Joined Together States had gotten access to computer technology by the end of 2005 [14].

TVET teachers prepare themselves and their students for a constantly changing environment. Education isn't simply confined to teaching the students according to a suggested plan at a specific school level. It has a great number of outskirt goals, destinations, and various thoughts. As a result, preparation is becoming an increasingly important tool in the fight against destitution, poverty, and the establishment of a propelled developed 
nation. The progression of information technology development in all spheres of life, including education, is a feature of modern society [14]. In general, the new advancements have been viewed as a significant activity in creating and improving educational and learning conditions. Technology is a growing part of any society today; the application of technology in education has become a cornerstone of any country's efforts to improve learners' performance in higher institutions. Education influences almost every area of our daily lives, and it covers different specializations. Education is a process in which learners gain knowledge and skills. The spread of knowledge has become crucial in this process, which has opened its doors to every technology that affects knowledge.

Despite the widespread benefits of ICT innovation in instruction, a report demonstrated that in recent years some nations in the developing African region were appraised lower than the world as far as ICT reception take-up in training [15]. Most technical and vocational educators have consistently had to cope with the problem of working with innovative technologies that are in steady condition of change. Besides, vocational instructional teachers consistently had the duty of preparing students for a changing world of work. These concerns serve as a suggestion to vocational educators that they don't have the luxury of resting on recently learned work abilities and information. Vocational instructors must keep themselves educated concerning contemporary improvements in their professional specialized expertise [16]. Research centers around the viability of computer use and its contributions to the education of specialized and professional courses, and technical and vocational teachers' caveats have been given insufficient consideration. limited and A predetermined number of studies have been conducted in regards to technical and vocational education teachers' impressions of computer utilization in teaching and learning. To address this gap, this paper aimed to investigate the competence needed by TVE teachers regarding computer and ICT tools for classroom teaching and learning. The anecdotal evidence about the quality of Technical and Vocational Education graduates in the world of work sounds different today when discharging duties, especially related to recent technologies, which lead to inadequate performance, low efficiency, and limited production in companies.

Most African countries are experiencing low-skilled labor shortages, which is hindering and jeopardizing their further economic growth and development. In order to fill this gap and control this crucial issue, technical and vocational education teachers constitute the main key factor. The instructive needs expanded when the computer innovation abilities were increasingly convoluted. Technical and vocational education teachers have consistently needed to adapt to the quandary or dilemma of working with innovative technologies that are in a steady state of flux since they have the obligation and responsibility of preparing individuals for the ceaselessly developing world of work. The computer and its related technology have become a significant instrument in higher education used for teaching and learning. It's a single instructional technology instrument that can be used in different subjects like science, technology, or language. [17-19] indicated that, generally, technical and vocational teachers in tertiary educational institutions in Nigeria don't have competence in computers and related technological advancements in their classrooms for teaching and learning.

Although technical and vocational education teachers are eager to advance in information developments, discoveries show that they have not yet reached the perfect ideal level [20]. The fast convergence of computer innovations into technical and professional vocational classrooms has left numerous professional educators ill-equipped to adequately use these contemporary instructional innovative technologies. Technical and vocational education teachers who lack competencies will lead to unproductive teaching and learning processes, which, in turn, might have a negative impact on the quality of the graduates. The competence of TVE teachers ought to be given more emphasis so as to guarantee the 
Technical and Vocational Education and Training graduates are of high caliber and are ready to address the issues in production sectors. Along these lines, this study attempts to investigate and portray the present expert skills, knowledge, clarity, and the preparation needs as to computer innovative technology competence among vocational and technical education teachers in Nigeria.

\section{Theoretical Framework}

The study conducted was backed by theory of reasoned action, theory of planned behaviour and trying theory. Theory of reasoned action (TRA) was developed by [21] as an improvement over information integration theory explicitly concerned with behaviour intention and persuasion, however it recognizes the situation that limit the influence of attitude on behaviour. The theory also uses two elements' attitudes and norms to predict behavioural intent. The theory stated that attitudes towards behaviours, subjective norms and perceived behavioral control, together shape an individual's behavioral intentions and behaviours [22]. The Expected Behavior Theory (TPB) has evolved from the Rational Action Theory. Taylor and Todd were the pioneers of the Theory of Planned Action in their study called "Understanding Information Technology use. A Test of Competitive Models," published in June 1995 (DTPB). The subjective norms (i.e., social influences), perceived behavioral controls and aspects of attitudinal attitudes are explored by this model. It splits them down into exact dimensions of beliefs. The trying theory (TT) promoted by [21] centers around the appraisal of attempting to act, focuses on the assessments of trying to act. In other words, attitudes towards reasoned activity are supplanted by attitude towards trying, and expectations are limited to goal and attempt [23] (see, Fig. 1).

\subsection{Conceptual Framework}

Education is not just a medium for information exchange and technology on a global scale, but also funding, a means of market struggle, a solution to geopolitical, socio-cultural, ethical problems as the computerization of education is increasing rapidly educators were considered competent when he/she has three element of competence such as knowledge, skills, and attitudes. Competent employees have the skills, capabilities, and knowledge in carrying out their duties efficiently and effectively, and competent teachers can change the progress of student learning [24].

\section{TVET Teacher}

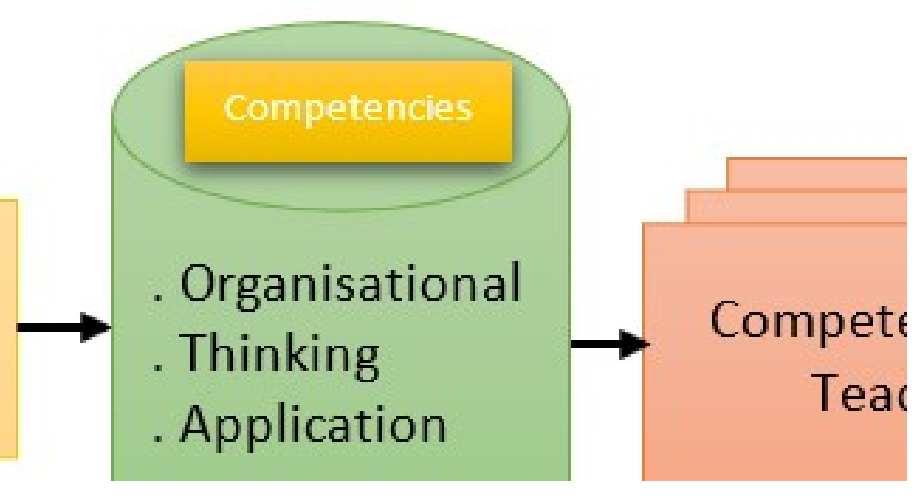

Fig. 1: Proposed Conceptual Frameworks 


\subsection{Concept Competence}

Historically, educational systems are the functional approach that has long prevailed and is predominant in many palaces. In the 1970s, there was a shift from the logic of content to an approach called goal teaching. Most school programs today agree on putting competence at the center of the curriculum. However, the notion of expertise is far from being fully stabilized. It is understood in many distinct ways and expressed in the curriculum across a certain number of variants. Competence derives from the Latin word "competere," which means "capable" and refers to a person's ability to have the desirable aptitudes, facts, frames of mind, attitudes, or lead to carry out a specific action. In this study [16], the word "competency" is used synonymously with the different term "mission." Competency is defined as the core of knowledge or abilities required to deliver key outputs. Competence is characterized, according to the Oxford Advanced Learner's Dictionary, as the ability to achieve something efficiently, productively, or admirably.

Competence is the collection of demonstrable competencies, features, and abilities that empower the effectiveness or enactment of a job to be improved. According to the business dictionary, competence is a collection of related skills, commitments, experience, and abilities that enable a person (or an organization) to behave effectively in a job or situation. Competence as the "ability to adequately apply learning outcomes in a defined context (education, training, job or career development)" is a qualification that is an accomplished learning outcome [25]. Competency is characterized as referring to those measurements of conduct lying behind equipped execution. In light of the fact that they are proposed to depict how individuals carry on when they do their jobs, they are frequently referred to as "conduct abilities." According to [26], competence is characterized as a set of related aptitudes, capacities, information, and conduct that can impact the achievement and quality of a labourers' activity. According to [26], competence is viewed as aptitudes, learning capacities, and conduct, which can impact the principal parts of specialized work. A person's competency is the capacity of a person to apply their learning aptitudes and disposition to finish a given errand that can be assessed. Taken together, competency can be characterized as the capacity to apply a lot of abilities, information, and attitudes that can effectively play out a given task or employment [27]. Classifications have been described as a specific, critical work section in an occupation. Within each order, a different number of progressively related abilities can be combined [28].

As indicated by the American Society for Training and Development (ASTD), competencies are characterized as the sign of a genuine profession. As never before, the American Society for Training and Development (ASTD) is supporting its individuals and the field of learning and improvement with a model intended to form the future of the profession. According to [28], competence is viewed as the conventional, coordinated, and disguised capacity to convey practical, compelling (commendable) execution (including critical thinking, realizing development, and making change) in a specific expert area, work, role, organizational setting, and task circumstance. Competence is characterized as "a perceptible or quantifiable capacity of an on-screen character to perform vital activity in an offered setting to accomplish explicit results." A worker should have cognitive skills (knowledge), interpersonal skills, and technical skills to achieve his or her work. In this study, there are three domains: technical competency, pedagogical competency, and personnel competency. Technical competence is the ability of a vocational teacher to apply knowledge and skills in the technical fields. Pedagogy competence is the ability of a teacher to teach and convey theoretical and practical subjects. Personnel competence is the attitude that should be developed by vocational teachers [28],[29], research competence is the mix of noticeable and quantifiable learning, aptitudes, capacities, and individual ascribed traits contributes to enhanced employee execution performance and eventually brings about hierarchical achievement. 
Competency is a critical factor in the evaluation of the standard of TVET teacher skills that is connected to talents, expertise, attitudes, beliefs, and appreciations that are considered vital elements of career growth [30]. [31]. In content delivery, skill acquisition, and classroom management, TVET teachers need to be competent. They should also be able to manage teaching aids, evaluate and evaluate pupils, provide good teaching methodology, understand the learning styles of students, address the students' demands within the classroom, and, most importantly, be a role model for learners [32]. TVET teachers are facing numerous challenges, not only in Nigeria but also in other parts of the world, especially in developing countries. TVET educators, for example, do not have adequate experience in the new technologies and pedagogy. This would undoubtedly impact the skills of TVET teachers and, in turn, jeopardize their career growth [33]. Pragmatic action will be used to solve the problem.

\subsection{Teachers Interpret and Teach Using Computer Technology}

According to [34] Computer competence is a broad term that is closely connected to related definitions of computer know-how, computer abilities, computer attainment, computer abilities and computer knowledge, [35]. The concept of computer skills has, in fact, evolved over time in line with changes and needs in the field of information technology. According to the International Society for Educational Technology (ISTE, 2008), developed criteria for teachers and computer competence among pre-service teachers for teaching technology integration. The standards included the efficient use of technology in teaching and the promotion of digital citizenship in order to boost students' creativity. Previous research on pre-service teachers' use of information technology in education has mainly focused on measures of self-efficacy, attitude, epistemological and pedagogical beliefs, and individual differences in ICT tools use [28].

\subsection{Technical and Vocational Education (TVET)}

TVET is a separate program that provides instructional methods that are both scientifically and basically distinct from other educational systems. The TVET education system is paired with special skills for individuals interested in the vocational sector. The learning processes are designed to be suitable for the manufacturing world, with an emphasis on practical skills and work-related issues [35]. TVET is a key part of national improvement designs in industrialized countries because of its effect on profitability, monetary and economic modern progression [36]. TVET with regards to this examination embraced the Federal Republic of Nigeria's definition in the National Policy on Education. [37] as a "thorough term alluding as the part of instructive educational procedure including, notwithstanding broad training to general education, the study of advancements and most sciences procurement of practical skills, attitudes, approaches, comprehension and information identifying with occupations in areas of the economic and social life".

TVET is generally accepted as a critical driving force for skills development. Global socio-economic growth and technological advancement to fulfil the goals and objectives of the consistency of the program needs to be strengthened and maintained by TVET in Nigeria [38]. Technical and vocational education is characterized as any form of training, collection, programming, students, or individuals that prepares them for useful work as semi-skilled laborers or expert specialists in a specific occupation.

As indicated by [38] The goal of TVET is to develop a person's aptitudes, skills, and information so that they can find work to live comfortably. Secondary schools in developing countries have Technical and Vocational Education organizations that prepare students for college. The primary goal of all TVET initiatives is to secure abilities and skills for beneficial work in a specific occupation or employment. Personal or paid jobs, as necessary for 
related planning and employment is the cornerstone of the majority of the most amazing practices and approaches clung to. One of the most important aspects of TVET is its emphasis on jobs, and the educational strategy also emphasizes the acquisition of skills for gainful employment. TVET arrangements are found to train the skilled laborers that the country needs in order to generate wealth and leave deteriorated penury. One distinguishing feature of TVE is that it is usually delivered at varying levels of difficulty. This implies that TVET will respond not only to the needs of various industries, but also to a variety of needs [38].

Technical and Vocational Education suggests qualifying instruction ways that provide people with occupation-explicit information and practical abilities, independent of the place, substance, and training provider [39] International Center for Technical and Vocational Education and Training., 2015). TVET is including training, preparing and aptitudes advancement identifying with a wide scope of word-related fields, generation, administrations and employments. TVET, as a segment of lifelong learning, can happen at all levels of education and incorporates work-based learning and keeping preparing and proficient advancement which may prompt capabilities. TVET additionally incorporates a wide scope of abilities advancement openings receptive to national and nearby settings. Figuring out how to learn, the advancement of proficiency and numeracy aptitudes, skills transversal abilities and citizenship aptitudes are indispensable segments of TVET [40].

TVET has a variety of objectives that differ by region. In Nigeria, TVET is part of the formal education system, which has been integrated into the three tiers of education (primary, secondary, and tertiary) in order to meet the nation's need for skilled labor and to improve the economic status of individuals and nations in general. Qualitatively TVET is widely recognized as the cornerstone of all growth, continuous improvement of the process is therefore necessary for the achievement of national TVET objectives, which will lead to the achievement of national objectives for the creation of quality human resources for self-sustaining national development. In Nigeria, TVE at post-elementary school level is planned to prepare students with the information, aptitudes and characteristics for the purpose of making a living (either independently employed or a business of work or be employable [42].

In line with this statement, the FRN in NPE states that:

"TVET is utilized as a distant coming to term alluding to those perspectives of the teacher procedure counting regardless wide broad preparing, the investigation of progresses and related sciences and the securing of practical and common-sense abilities, aptitudes, outlines of intellect, understanding and information distinguishing with occupations completely different divisions of the economic and open action NPE [37] ".

The policy further states that, the goals of TVET are:

i to give prepared labour in the applied science and business particularly at craft, advanced art and specialized technical and vocational levels.

ii to give the specialized and professional abilities important for Agricultural, business and monetary improvement;

iii to give preparing and impart important abilities to individual who will be self-reliant economically NPE [37]. 
Incompatibility of the expressed objectives, the national policy on education further expresses that: The trainees completing technical college programs shall have three alternatives:

i) Secure work toward the finish of the entire course or after finishing a couple of modules of employable abilities.

ii) Set up their own business and become independently employed and be able to employ others;

iii Pursue further training ahead of time create/technical program and in tertiary specialized technical establishments, for example, science and technical schools, polytechnics or universities of education (technical) and universities NPE [37].

\subsection{Competence to Integrate Computer in Technical and Vocational Education (TVE)}

Competence in TVE is gained by completing tasks that assist a person in acquiring employable skills. Individuals who are competent can apply knowledge and skills, as well as demonstrate attitudes related to expected job activities, in the teaching and learning processes [41]. This proliferation of emerging technology greatly impacts the regular lives of individuals. Indeed, with regard to societal interaction, teachers view digital communication technologies as indispensable [42]. Abilities to facilitate Computer innovations technology instruction can be portrayed in different manners. Various affiliations have outfitted structures with Computer capacities for teachers. In different Computer innovation frameworks, for instance, modernized capability, ICT in education and ICT aptitude. [43] Computer Technologies capacities recommended the specific usage of Computer Technologies, which conceptualized as the fused and valuable use of advanced information, aptitudes, and perspectives. According to [27], the meaning of Computer Technology competency shifts within a tight specialized abilities-based concentration to a more extensive progressively all encompasses idea of structure academic information about innovation including both instructional devices and psychological to encourages students learning. This study is presented because the computer has the potential to increase teacher competence and student motivation. As a result, the school has been asked to use the computer as an instructional assistant [44].

\subsection{Technological Pedagogical Content Knowledge (TPACK) Model}

TPACK is the complex knowledge among technology, pedagogy, and content. TPACK is good basic teaching with technology, pedagogic technic is technology that uses in a constructive way to teach the content, the knowledge of what makes that concept its hard or easy to learn and how technology can overcome some problem faced. TPACK explain teachers abilities on how to teaching and learning will be carried out from certain content through pedagogy approach and technology in the curriculum because teaching and learning is found within the integration between computer application technology. [45].

The rapid proliferation of ICT tools in the $21^{\text {st }}$ century is through analysis of TPACK and teacher interaction capabilities. There are seven variables which influence TPACK namely (1) Technological Knowledge (TK) is the study about how to operate computer and relevant software, (2) Pedagogical Knowledge (PK) is the ability in learning management, (3) Content Knowledge (CK) is the subject matter such as Science, Mathematics, language and so on, (4) Technological Content Knowledge (TCK) is knowledge study about how the content can be examined or represent by technology such as using computer simulation to represent and study network topologies, (5) Pedagogical Content Knowledge (PCK) is 
knowledge how to represent and formulate subjects that make it understood by students, (6) Technological Pedagogical Knowledge (TPK) is knowledge about how technology can facilitate pedagogical approaches such as using game design to support practicum about OSI Layers computer networks, (7) Technological Pedagogical And Content Knowledge (TPACK) is knowledge about how to facilitate student learning from certain content through pedagogical and technological approaches (see, Fig. 2).

With suitable pedagogical approaches and selected technologies, TPACK can be viewed as an intuitive understanding of teachers for teaching subject-specific content. Teaching is a dynamic cognitive task that allows teachers to draw on many forms of information. It is well understood. TPACK serves as a valuable conceptual tool for thinking, assessing, and reviewing what teachers need to know in order to incorporate technology into teaching, but ultimately it needs to be used as a framework for how teachers can better develop this integrated knowledge [46].

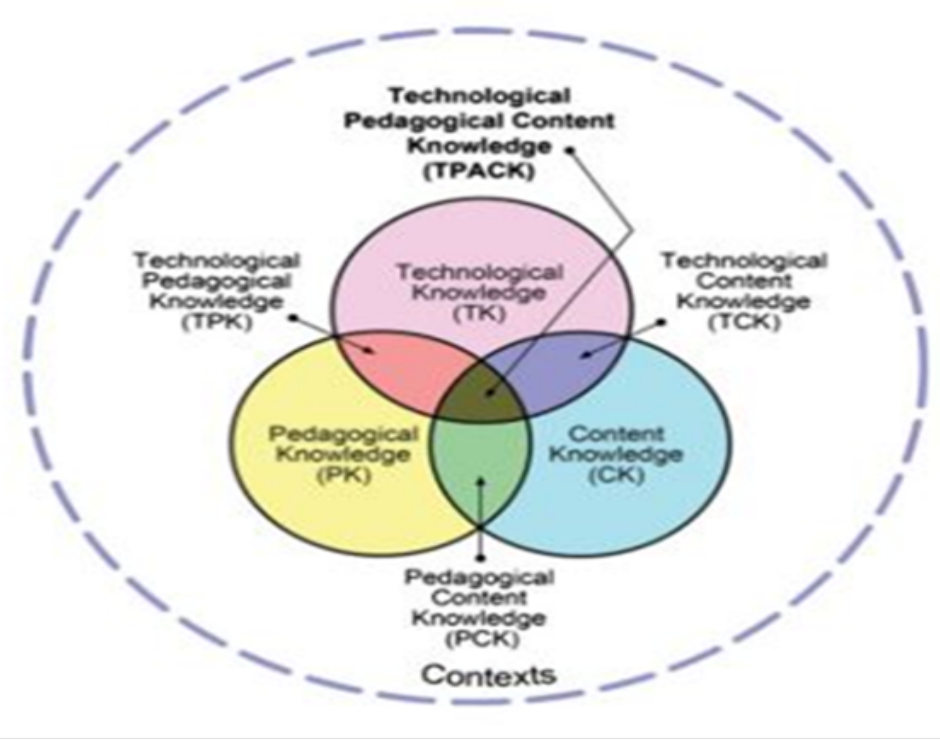

Fig. 2: The TPACK framework illustration is adapted from http://tpack.org.

\subsection{Technological Knowledge (TK)}

TK is the basics of technology that can be used to support learning. For this reason, teachers need mastery in information processing, communicating with ICTs in learning. Furthermore, mastering this technology is the demand of the 21st century [45], knowledge about various traditional and new technologies.

\subsection{Pedagogical Knowledge (PK)}

PK describes knowledge in depth related to the theory and practice of teaching and learning which includes goals, processes, assessment learning methods, strategies, and others. Pedagogical knowledge needs an considerate of cognitive, affective, social aspects and the development of learning theory and how it can be applied in the learning process [45]. [47]"Understanding of how specific subjects, issues, or problems are structured, addressed, and adapted to the diverse interests and skills of learners;" and the " most valuable ways of representation of these concepts, most effective analogies, diagrams. [48] Awareness of educational methods, concepts and techniques for the management of classrooms and the coordination of subject matter teaching. 


\subsection{Content Knowledge (CK)}

CK communicates the information instructors got to instruct almost their field [49]. The perception within a field of research of knowledge systems, concepts, theories and skills (Shulman, 2004:[47]). domain-specific knowledge about the subject matter that teachers are supposed to teach [48].

\subsection{Technological Content Knowledge (TCK)}

TCK is included in understanding innovation and subject matter that can offer assistance and impact other components. Formulating instructional goals, there is often misconception and scientific ego. For example, people who are experts in ICT are positioned as people who are only in the ICT field. In fact, ICT experts are needed as a catalyst, which is to facilitate understanding of subject matter [45]. Awareness of technical material recognizes technology in a particular topic or discipline; it reflects technology [47].

\subsection{Pedagogical Content Knowledge (PCK)}

PCK includes the interaction and occurrence of intersection between pedagogy (P) and subject matter (C). This includes the learning process related to the subject matter being studied as well as the learning participant assessment system. The learning model is expected to make learning participants effectively [45]. According to [47]. PCK: is the category of educational fabric mindfulness incorporates the foremost regularly instructed concepts in one's subject range, the foremost useful shapes of representation of those thoughts, the foremost compelling analogies, charts, examinations, depictions, and exhibits, in a word, ways of speaking to these thoughts.

\subsection{Technological Pedagogical Knowledge (TPK)}

TPK is a series of understanding how learning changes occur by utilizing the technology used to support active learning and can assist and simplify the concepts of the subject matter. In fact, with the presence of ICTs in learning optimally to open insights, participants learn to understand the subject matter that is microscopic, abstract and complex. This is the role of ICT tools can be interpreted as a source of learning [45]. As opined by [47] Technological pedagogical knowledge gets it how innovation can shape the ways of educating.

\section{Materials and Methods}

\subsection{Complete Research Method}

The research aimed to investigate technical and vocational education teachers' computer and some ICT tools competence, relationship between computer and ICT technologies competencies (dependent variables) through the TPACK design model and different types of independent variables with teacher's demographic background. In the study, the TPACK design model was applied to obtain the data from the technical and vocational education teachers through questionnaires.

The Bauchi and Gombe states in Nigeria were chosen for the research study because they have six (6) higher educational institutions offering technical and vocational courses, namely Abubakar Tafawa Balewa University Bauchi (ATBU), Aminu Saleh College of Education (COE) Azare, and Abubakar Tatari Ali Polytechnic (ATAP). Institutions in Gombe include the Gombe State University (GESU), the Federal College of Education 
Technical (FCE) Gombe, and the Gombe State Polytechnic Bajoga. The two states were chosen because they share the same cultures and traditions.

Bauchi state was established in 1976 when the former northeastern state was divided, and it originally included the region now known as Gombe state, which became a distinct state in 1997 created out of Bauchi. Only technical education institutions that have been in operation for more than seven years will be included in this report [50] claimed that it will take about seven to thirty years for an organization/ institution to enter maturity level. Matured organization/ institution will be involved in this study for several reasons:

(i) All programs are functioning well and recognized in the community,

(ii) Larger and more culturally diverse and specialized staff,

(iii) Efficient and standardized operations.

\subsection{Research Sample}

Agreeing to [51] population alludes to the entire number of individuals or objects that can be included as investigate subject. It might also be alluded to as comprising of the entire set of people that the researcher is curious about and to whom the discoveries of the investigate can be generalized. This non-experimental consider gives numeric description or opinions of a population by consider a test of that populace [52]. The sample of this investigate study were instructors who epitomized a better level of education in specialized and professional instruction in these states. According to [53] Cluster sampling is typically used when the population is very large, such as when sampling a region, state, or nation. The sampling population is divided into groups called clusters, and elements are selected from each cluster. The justification for the choice of cluster sampling in this study is that the population of the study is spread across two (2); therefore, in order to save cost, time and transportation cluster sampling was utilized for the study [53].

\subsection{Research Instrument}

The study data were collected through the use of structured questionnaires; the study survey comprises of three parts. The primary portion 1 contained the study consent form, which introduces the study to the members, highlights the reason of the research, and what is required from the teachers concerning the survey It moreover states the benefits and risks associated with partaking within the research which cooperation is voluntary. Whereas the second portion of the survey contained respondents' demographic information such as age, sex, years of teaching experiences, level of education and forty-four (44) questions from the three constructs: computer operation skills, perception of computer technology, and attitudes towards computer technology usage, using 5-point Likert scale 1= Strongly Disagree, 2= Disagree, 3= Neutral, 4= Agree, and 5= Strongly Agree. The questionnaire was validated by five experts, three including language expert from the Educational Sciences Near East University Nicosia Cyprus and two subject experts from Abubakar Tafawa Balewa University Bauchi Nigeria and Aminu Saleh College of Education Azare Cronbach alpha of 0.89 was obtained. The statistical analyses between the variables are presented in Table 1. Statistical analysis is for the most part utilized to get it the science of the information to explore the common issues that can lead to erroneous comes about as well as a legitimate choice-making based on the crude information. 
Table 1: The statistical analysis between the variables

\begin{tabular}{lllllll}
\hline Variables & Mean & Median & Mode & SD & Minimum & Maximum \\
\hline LE & 2.0500 & 2.0000 & 2.0000 & 0.7462 & 1.0000 & 3.0000 \\
G & 1.2000 & 1.0000 & 1.0000 & 0.4034 & 1.0000 & 2.0000 \\
A & 2.7167 & 3.0000 & 3.0000 & 0.5237 & 1.0000 & 3.0000 \\
TE & 2.8500 & 3.0000 & 3.0000 & 1.0055 & 1.0000 & 4.0000 \\
C & 3.6564 & 3.6932 & 3.5682 & 0.3828 & 2.4091 & 4.3182 \\
\hline
\end{tabular}

${ }^{1} \mathrm{LE}=$ level of Education, $\mathrm{G}=$ gender, $\mathrm{A}=$ age, $\mathrm{TE}=$ Teaching Experience, and $\mathrm{C}=$ Competence.

\subsection{Artificial Intelligence (AI) and Regression Models}

\subsubsection{Artificial Neural Network (NN)}

Artificial Neural Network (ANN) is the foremost common utilized discovery model because of its promising ability, capacity to anticipate or predict and illuminate highly complicated or complex input-output relationship. ANN is a framework structured subordinate on computational investigation so as to mimic and imitate the strategy where human brain handles the information [54]. It involves various neurons as processing units which are associated with customizable weight and inclinations. Back Propagation Neural Network (BPNN) is among the comprehensively used ANNs. In BPNN, the setting of learning is alluded to as a ceaseless method through which the tendencies and the affiliation loads are adjusted till the yield is acquired.

This procedure may be managed or even unsupervised. The supervised learning is commonly utilized so as to limit the between the figured and the ideal worth [47]. Learning rate expect a huge activity by portraying the knowledge of the organization through joining the organization framework system and in this manner restricted the issues of close by least. The fundamental purpose of Back Propagation Neural Network (BPNN) is to decrease the blunder all together for the framework to get comfortable with the readiness data. Sigmoid and the Lavenberg-Marquardt (LM) were utilized as actuation restrain and calculation, separately as presented in Fig. 3.

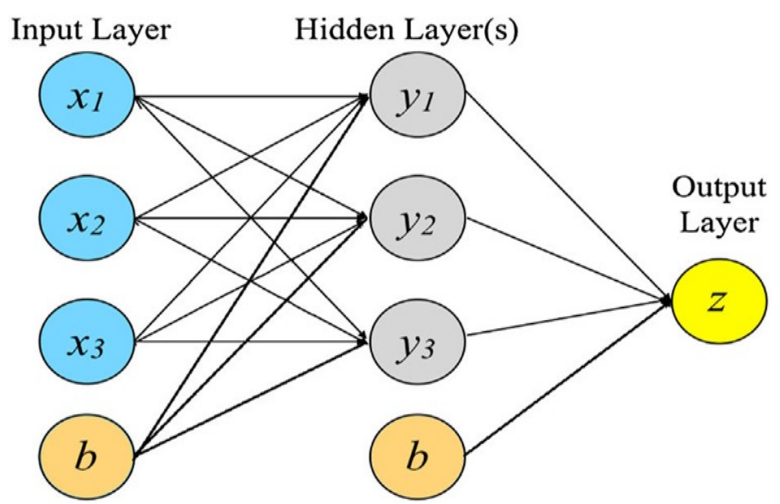

Fig. 3: Artificial Neural network (ANN)

\subsubsection{Adaptive Neuro-Fuzzy Inference System (ANFIS)}

Adaptive neuro-fuzzy inference system (ANFIS) or neuro-fuzzy (NF) or non-direct model Filled in as one staggering displaying device because of the way wherein NN's 
learning capacity and fuzzy logic (FL) are both used to make a steady half breed framework structure. ANFIS has been filled in as the general approximator that mixes NN and FL's capacity to make a system fit for managing complex non-straight associations between a great deal of information and yield [55]. Generally, Tsumoto, Sugeno, and Mamdani are three sorts of ANFIS, to be explicit Tsumoto, Sugeno, and Mamdani, whereby the Surgeon's framework structure has more broad applications. There are various kinds of interest work, for instance, three-sided, sigmoid, Gaussian and trapezoidal. The overall structure of ANFIS is showed up in Fig. 4. FL was shown to hand questionable wonders participated in any methodology and incorporates the change of data into fluffy characteristics through the use of cooperation limits. Hubs that fill in as participation capacities (MFs) essentially as grants the appearing between the relations of the commitment with the abdicate. There are different sorts of intrigued restrain, for instance, three-sided, sigmoid, Gaussian and trapezoidal [56]. Below shows an architecture of ANFIS.

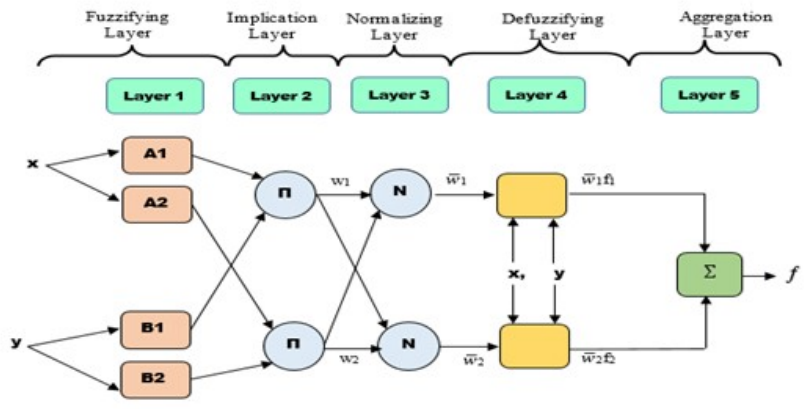

Fig. 4: Schematic structure of Adaptive Neuro-fuzzy inference system (ANFIS)

\subsubsection{Multilinear Regression (MLR)}

Regression models generally predict the extent of the correlation between the parameters of inputs and outputs, as well as the relationship between them. Linear regressions are usually fitted using the least square approach, although other methods can be used equally, such as limiting the "lack of fit" in some of the standards or reducing the penalized variant loss of the least square function as for the ridge regression. Linear regression is primarily separately categorized into two major product divisions and simple linear regression. Linear regression is considered easy if a single input variable is used to predict the association between a single output. However, the purpose is to calculate the relationship among two or more input variables in order to evaluate a model, the variables of the unit criterion are known as multi-linear regression. MLR, in which each value of the input parameter is associated with the output variable value, is the most commonly used form of linear regression used in various fields of study. It is known that MLR shows a straight-line correlation in terms of excellent estimates of all data points concerning both the output and the target variables. As per [57] [58] MLR model is the broadly utilized sort of linear regression includes an investigation whereby each esteem from the independent factors is recognized with a dependent subordinate variable worth. Commonly, MLR incorporates the estimation of the degree of association that exists between a single reaction variable for illustration the dependent and two or more indicators for illustration free components.

\section{Discussion}

Vividly, digital and analogue technologies is likely to be extensively used for teaching and learning in all levels of education, despite the limitations, the study contributes to the literature on TVE teacher's competence for computer educational technology use in several ways. The study also examines the influence of computer and re- 
lated ICT technologies among technical and vocational teachers' competencies toward use of these technologies in their classroom teaching, and explored the relationship between technical and vocational teacher's computer competencies with their demographic background, data collected in two states higher educational institutions technical and vocational education teachers in northeastern part of Nigeria. Two different AI-based models (ANN and ANFIS) and one classical model (MLR) were employed to prognosticate/prediction of competencies (C) using different input variables known as dependent variables. For any data-driven techniques such as ANN, ANFIS and MLR, data pre-processing is quite important in order to determine the proper output. As such correlation matrix between the observed data were carried in order to evaluate the strength and relationship between the variables. The raw data of both the input and output can be visualized in figure 5 .

Table 3 appears the Spearman Pearson relationship between the dependent and independent factors. Spearman Pearson relationship characterizes how well the relationship between the factors can be depicted employing a straight work. The strength of the correlation isn't subordinate on the course or sign. A positive coefficient shows that increment within the first parameter would compare to an increment within the second parameter, whereas a negative relationship demonstrates an converse relationship whereby one parameter increments and the second [59]. It can be seen from Table 2 shows there is a high correlation between $\mathrm{C}$ and TE, then Age, educational level and Gender. The correlation of C and G is 0.04839 indicate that there is less relationship between the two variables. While the strong relationship was indicated to be with TE. The result is similar to the study conducted by [34]. There's a significant and positive relationship among computer competence, attitude towards CAE, and deliberate to innovation acknowledgment. Seen convenience and satisfaction have positive relationship with attitude towards CAE. In spite of the fact that perceived ease of utilize additionally has a significant positive relationship with the attitude towards CAE, it does not anticipate the attitude towards it.
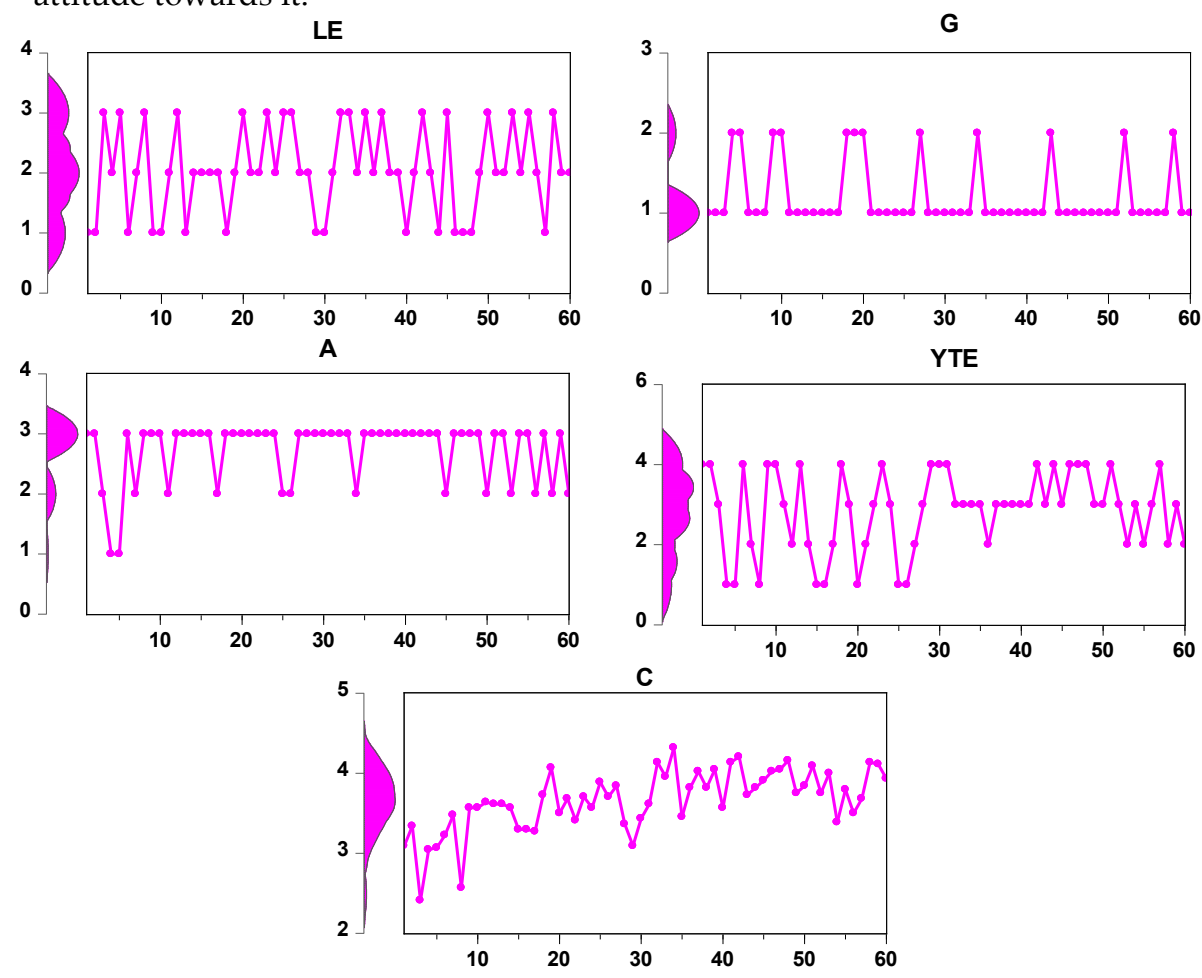

Fig. 5: The trends of the raw data used in this study 
Table 2: Spearman Pearson correlation

\begin{tabular}{llllll}
\hline Variables & LE & $G$ & $A$ & $T E$ & $C$ \\
\hline LE & 1 & & & & \\
G & -0.03379 & 1 & & & \\
A & -0.35347 & -0.20859 & 1 & & \\
TE & -0.57719 & -0.13372 & 0.465081 & 1 & \\
C & 0.058458 & 0.048393 & 0.161418 & 0.222111 & 1 \\
\hline
\end{tabular}

For the improvement of the models, MATLAB 9.3 (R2019a) was utilized within the ANN and ANFIS models, whereas the classical linear MLR demonstrate was created utilizing the SPSS software. Finding suitable hidden nodes is the basic include of any ANN show in arrange to side-step overfitting problem. As has been detailed in several works of literature within the field of science and engineering, there's no exact standard strategy for determining the suitable number of hidden neurons. In this consider, trial and mistake strategies were utilized to the assurance of covered up neurons. For the case of ANFIS demonstrate, various sorts of enrollment capacities (MFs) and epoch cycle were investigated utilizing trial and mistake to distinguish the leading structure. Table 3 appears the comes about of the execution analysis for the utilized approaches.

Table 3: Performance efficiency of the models

\begin{tabular}{llllllllll}
\hline & & \multicolumn{3}{c}{ Training } & \multicolumn{5}{c}{ Testing } \\
Model & Variables & $\mathbf{R}^{2}$ & RMSE & MSE & $\mathbf{R}$ & $\mathbf{R}^{2}$ & RMSE & MSE & $\mathbf{R}$ \\
\hline MLR & LE+G+A+TE & 0.3574 & 0.3696 & 0.1366 & 0.5978 & 0.3141 & 0.4096 & 0.1439 & 0.5604 \\
ANN & LE+G+A+TE & 0.4376 & 0.3033 & 0.0920 & 0.6615 & 0.4035 & 0.3198 & 0.1089 & 0.6352 \\
ANFIS & LE+G+A+TE & 0.5485 & 0.2580 & 0.0666 & 0.7406 & 0.5274 & 0.3140 & 0.0986 & 0.7262 \\
\hline
\end{tabular}

From Table 3, it's clear that the ANFIS model provides higher accuracy than both ANN and MLR model for the prediction of C using LE, A, G, and TE. However, with respect to goodness-of-fit (R2) the performances of the three models are not satisfactory for the prediction of $\mathrm{C}$. This is because of the low correlation coefficient attained between the variables and the target value. Even though the prediction results in terms of R2 is very low, but AI-based models have shown the promising capability and wider percentage differences with regards to the traditional linear models. According to the results from Table 3, it can be quantitatively conclude that ANFIS model as universal approximate increased the prediction percentage over ANN and MLR over up to $11 \%, 12 \%$ and $19 \%, 21 \%$ for training and testing, respectively. This powerful nature of ANFIS could attributed to the hybrid nature of it is algorithm that is to say ANFIS consist of the knowledge of ANN and fuzzy logic. More comparison of the results can be visualized using the box-plot diagram shown in Fig. 6. From the plots, it can be observed that the ANFIS model was spread with the agreement of the observed value (C). Finally, the extend of the far and near outliers are associated with MLR and ANN models this justified the prediction performance of the ANFIS model. 


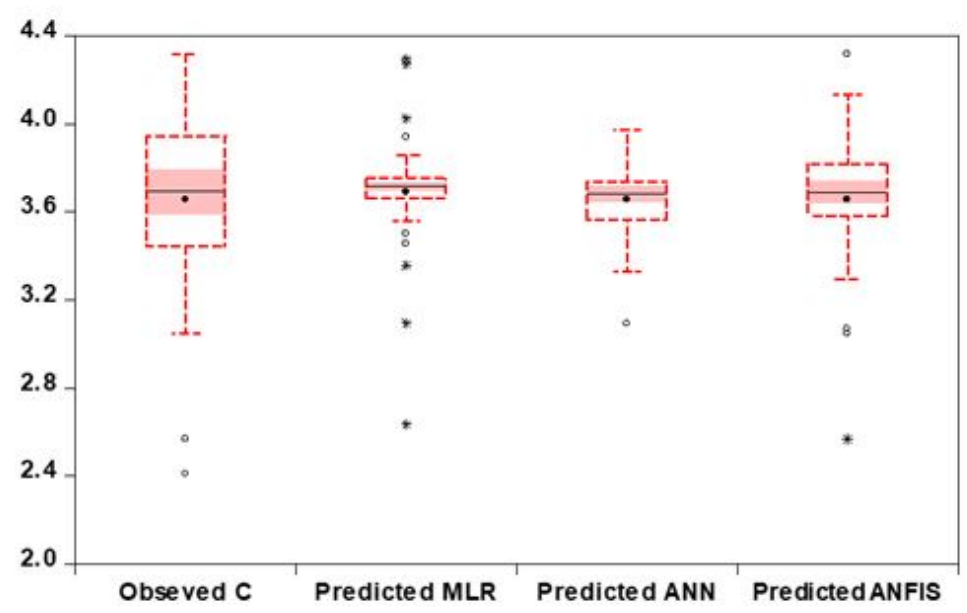

Fig.6: Box-plot between observed C and predicted model

Furthermore, the predictive results can be described in terms of correlation coefficient, generally the higher the $\mathrm{R}$ the better the prediction accuracy. It was reported by [60] [59] [58] that the correlation value greater than or equal to 0.7 is satisfactory. Hence, according to the results obtained from Table 3 ANFIS with $\mathrm{R}=0.7406$ and 0.7262 for both training and testing phase, respectively emerged satisfactory. This conclusion can also present in radar chart diagram also called spider chart (Fig. 7)

\section{(A) TRAINING-C}

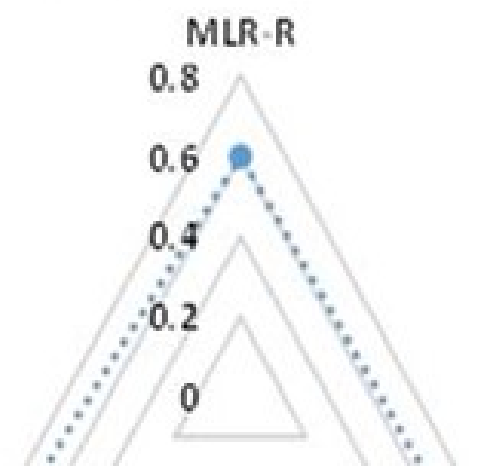

(B) TESTIN

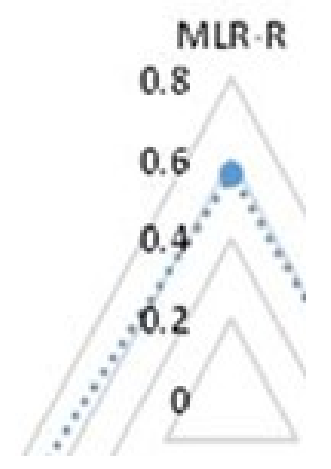

Fig. 7: Radar chart diagram of ANFIS, ANN and MLR models

With regards to error differences, the three models were evaluated in terms of MSE, as shown in Table 3. The error graph is presented in Fig. 8, from the figure it can be seen that the ANFIS model outflanked the other two models and therefore proved merit. The prediction accuracy of the ANFIS model is quite promising due to the fact that the ANFIS model reduced the prediction error by $2 \%, 1 \%$ and $7 \%, 4 \%$, for ANN and MLR in both training and testing phase. The incapability of MLR regression is associated with it is linearity pattern of handle the data. The overall comparisons of the three models are presented in Fig. 9. From the figure it can observed that predicted valued form both the three models are graphically demonstrated and visualized in respect of scatter plot, histogram to shows the distribution and the unique R coefficient among the three models. 
Error Performance Criteria for - C

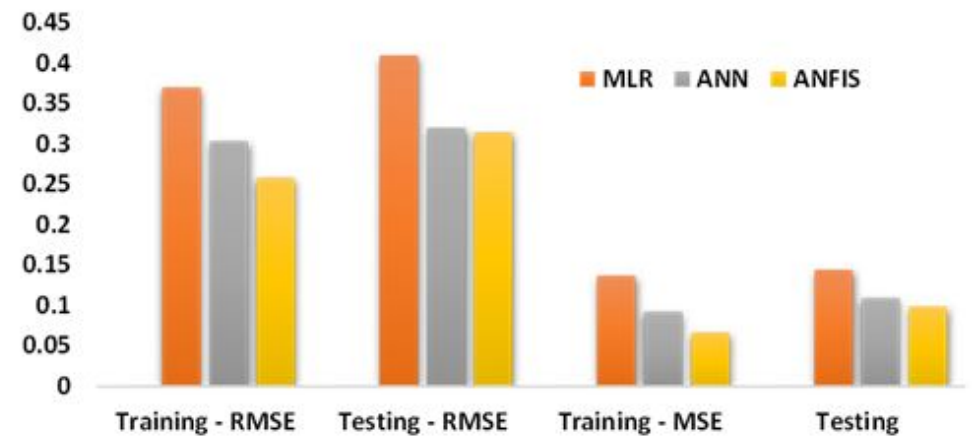

Fig. 8: Error bar graph of three models

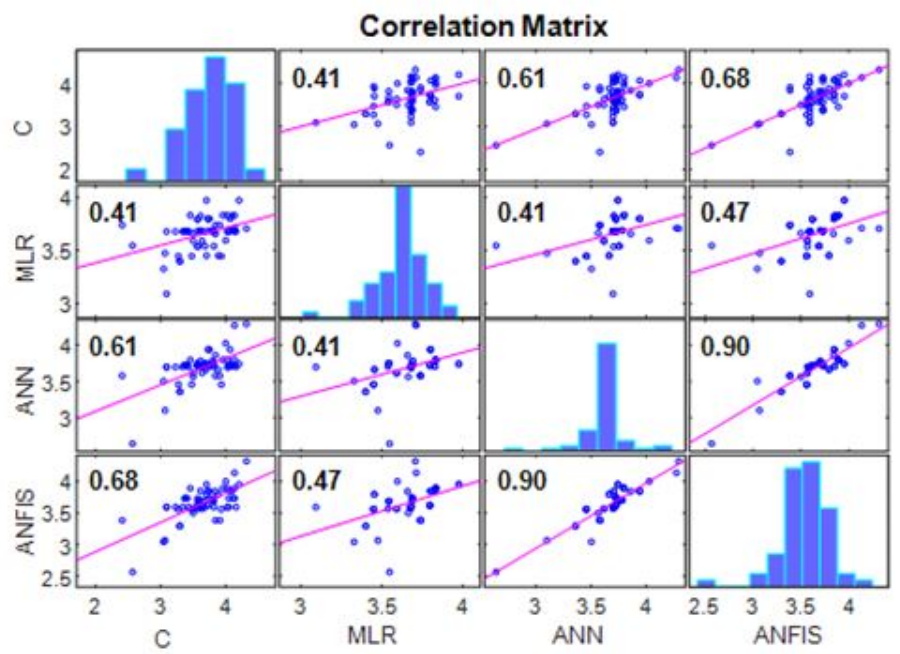

Fig. 9: General comparison between three models in terms of scatter plot, histogram and $\mathrm{R}$

\section{Conclusions}

Despite the fact that technology has always played a significant role in human life, it has only recently evolved into an integral part of our everyday lives. It was doubtful that education would not fall behind at a time when technology was being absorbed so quickly. As evidenced by the continuous computer ICT tools participation of the educational needs of teachers in OECD TALIS [61] studies, expertise in technology has become a need rather than a need for educators. The fact of technology's incorporation into education has therefore become an important factor in the academic climate [62]. It is not enough simply to make teachers competent in technical knowledge in a faithful way like education that has to be considered in many aspects and has many affecting variables.

This finding is similar to those of [30] competencies are actually those aptitudes, learning, mentalities, and qualities that are identified with educating and preparing inside the circle of TVE and training. Also similar to the study conducted by [63] According to the report, teachers' ICT skills were mild, and the tremendous larger part of 
instructors who taken part in this think about were direct users of computer ICT devices within the classroom. Teachers' ICT skills differed significantly based on demographic factors such as gender, age, years of teaching experience, and type of ICT training. Furthermore, this study was consistent with that of [64] that educators in Nigerian tertiary establishments have specialized aptitude on computer to empower them to show students with computer technologies in order to be competent teachers. Similar to study conducted by [65] which emphasized that these days the utilization of innovation isn't a benefit, yet a commitment in order to make learning more retention and provide teachers competency.

Similar study conducted by [66] TVE teachers competency in Computer innovation is fundamental on the chance that they are to be successful instructional leaders as they use and move this competency to their students. A study conducted by [67] demonstrated that educators in the two nations had a positive attitude toward the utilization of Computers and other technologies tools in schools. They regularly imagined that Computers may create teacher's inspiration, abilities, intrigue and accomplishment in the event that they were utilized successfully. They likewise imagine that the future will be founded on the knowledge, information and innovation, also the result is in line with the study conducted by [41] teachers should apply their computer teaching expertise and skills and use their business experience to contribute to a wider understanding of knowledge and teaching in order to establish successful strategies in the area of TVE. Furthermore, to determine if there any relationship between competencies in technical and vocational teachers with their demographic background, the study indicate a high correlation between competency and years of teaching experience flows by competency and age, competency and level of education and competency and gender.

The correlation between competency and years of teaching experience while the least is correlation between competency and gender about 0.04839 . This result support the study conducted by [31] examine teachers' attitude and perceived competency towards computer and ICT tools technology the result shows that must teachers who had encouraging knowledge running between nine to fourteen years (9-14ys) has a positive attitude toward the use of computer technologies. According to [68] his study demonstrated a huge contrast between the male and female teachers towards Computer innovation aptitudes, the connection among attitude and competency was least but significant as the connection among gender and competency was noteworthy related. The findings of the study is similar to the study conducted by [69] showed that expertise, abilities, and characteristics played a major role in ensuring the degree of competency of teachers. Along with the results, the teacher's comprehension was found to be the most important factor in defining the competence of TVET teachers. The result is similar to study conducted by [14] also found that teachers needed ongoing support and opportunities to gain trust in the use of ICT, experiment with new technologies. Long-Term Continuous teacher growth, knowledge sharing among trainers, Partnerships and teacher engagement and encouragement from educators and leaders. Administrators were also significant factors affecting the willingness of teachers to integrate in their lectures, ICT. Based on the results of the current report, it is proposed that the computer knowledge and skills of teachers should be continually assessed in order to enhance their competency in the use of computers. In addition, measures for mandatory implementation of computer-based content delivery are recommended; computerized pre- and non-instructional practices. It is important to consistently develop the level of computer skills through daily training sessions. The more trained teachers are in technology, pedagogy, and technology and pedagogy integration, the more computers are used in the process of teaching and learning. Therefore, because teacher competence in the use of computers may be an important factor in deciding the use of computers, it is assumed that an awareness of different competencies related to the use of computers by teachers 
will empower policymakers and decision-makers with useful knowledge to support the formulation of strategies to implement the widespread adoption of computer use in the teaching and learning process. These variables should, therefore, be taken into account when educating. The authorities decided to encourage teachers to take full advantage of the use of ICT to improve. Method of Teaching-learning. Leaders in the Nigerian ministry of education empower technical and professional vocational instructors to upgrade their computer and innovation related abilities so as to have the option to coordinate innovation in their classes. In conclusion, in case innovations to be utilized as a apparatus to bolster the instructive destinations such as aptitudes for discoveries and surveying data participation, communication, and issue understanding which are crucial for the planning of students for the information within the society.

Furthermore, the results of this study contribute to existing research regarding teachers Since TVE teachers in Nigerian tertiary institution have competencies in using computer and ICT tools technology in their classroom and think about the gadget as valuable for instructing, it's suitable to guarantee that satisfactory opportunities available for Nigerian TVE teachers to use them and beyond. Hence, instructors will be able to successfully create the competencies required to instruct with computer innovation as it were when specialized and professional teacher's teachers systematically implant innovation all through the instructor instruction arrange of educating or educational modules. Recommendations for teachers and professional development there is no barrier to computer technology training among all teachers regardless of their levels and computer training experiences. Further study can conduct using the same methodology but in different states and zones in Nigeria in order to generalize the results. This research is quantitative, but further research could be qualitative or mixed-method through interviews, observation and questionnaires to get in-depth information about computer technology competencies among TVE teachers.

Funding: Please add: "This research received no external funding"

Conflicts of Interest: Declare conflicts of interest or state “The authors declare no conflict of interest."

\section{References}

1. Jyoti Bhalla, D. Computer Competence of School Teachers. IOSR J. Humanity. Soc. Sci. 2014, 19, 69-80, doi:10.9790/0837-19136980.

2. Anane, C.A. Competency-Based Training: Quality Delivery For Technical And Vocational Education And Training ( TVET ) Institutions. Educ. Res. Int. 2013, 2, 117-127.

3. Kamin, Y. Bin; Bin Saud, MS; Yahaya, N.; Al-Rahmi, W.M.; Latib, A.A.; Ahmad, A.; Amin, N.F.; Cartledge, D. Comparative Analysis of Students Perception on the Relevance of Diploma Certificate in Automotive Engineering to the Industry. IEEE Access 2018, 6, 79129-79137, doi:10.1109/ACCESS.2018.2883694.

4. Aydin, S. Teachers' perceptions about the use of computers in EFL teaching and learning: The case of Turkey. Comput. Assist. Lang. Learn. 2013, 26, 214-233, doi:10.1080/09588221.2012.654495.

5. Atman Uslu, N.; Usluel, Y.K. Predicting technology integration based on a conceptual framework for ICT use in education. Technol. Pedagogy. Educ. 2019, 28, 517-531, doi:10.1080/1475939X.2019.1668293.

6. Asenso-okyere, K.; Mekonnen, D.A. The Importance of ICTs in the Provision of Information for Improving Agricultural Productivity and Rural Incomes in Africa. UNDP Work. Pap. 2012-015 2012.

7. Oladosu, K. Basic Technology Teachers' Awareness and Attitude Towards the Use Of Information and Communication Technology For Sustainable Development in Lagos State Education Districts: I , IV and VI. 2012, 3, 46-51.

8. Grosch, M. Developing a Competency Standard for TVET Teacher Education in ASEAN Countries. J. Pendidik. Teknologi. dan Kejuru. 2017, 23, 279-287, doi:10.21831/jptk.v23i3.13418.

9. Romeo, G.; Lloyd, M.; Downes, T.; Finger, G.; Albion, P.; Jamieson-proctor, R.; Cavanagh, R.; Grimbeek, P.; Lloyd, M.; Fitz Gerald, R.; et al. Teaching teachers for the future: How, what, why, and what next? Geoff Romeo - Australian Catholic University Marg Lloyd - Queensland University of Technology Toni Downes - Charles Sturt University. 2013, 28 , 2-12.

10. Sweeney, T.; Drummond, A. How prepared are our pre-service teachers to integrate technology? a pilot study. Aust. Educ. Comput. 2013, 27, 117-123. 
11. Goldman, Z.W.; Martin, M.M. Millennial students in the college classroom: adjusting to academic entitlement. Commun. Educ. 2016, 65, 365-367, doi:10.1080/03634523.2016.1177841.

12. Dogara, G.; Saud, M.S. Bin; Kamin, Y. Bin Work-Based Learning Conceptual Framework for Effective Incorporation of Soft Skills among Students of Vocational and Technical Institutions. IEEE Access 2020, 8, 211642-211652, doi:10.1109/ACCESS.2020.3040043.

13. Yaseen, ZM; Ehteram, M.; Hossain, M.S.; Fai, CM; Kong, SB; Mohd, NS; Jaafar, WZB; Afan, HA; Hin, LS; Zaini, N.; et al. A novel hybrid evolutionary data-intelligence algorithm for irrigation and power production management: Application to multi-purpose reservoir systems. Sustain. 2019, 11, doi:10.3390/su11071953.

14. Hassan Mirzajani; Rosnaini Mahmud; Ahmad Fauzi Mohd Ayub; Wong, S.L. Teachers' acceptance of ICT and its integration in the classroom. Qual. Assur. Educ. 2006, 14, 251-267.

15. Scherer, R.; Tondeur, J.; Siddiq, F.; Baran, E. The importance of attitudes toward technology for pre-service teachers' technological, pedagogical, and content knowledge: Comparing structural equation modeling approaches. Comput. Human Behav. 2018, 80, 67-80, doi:10.1016/j.chb.2017.11.003.

16. Michael, A. \& John, F.L. A handbook of personnel management practice. Acad. Med. 2002, 89, 236-243, doi:10.1097/ACM.0000000000000086.

17. Prasad, N.; Murdoch, D.R.; Reyburn, H.; Crump, J.A. Etiology of severe febrile illness in low- and middle-income countries: A systematic review. PLoS One 2015, 10, 1-25, doi:10.1371/journal.pone.0127962.

18. Sofa N. : Research Trends of Aerial Image Reproduction Stereoscopic Image. Nhk 技研 2015, 151, 10-17.

19. Isiyaku, D.D.; Ayub, M.A.F.; Abdul Kadir, S. Antecedents to teachers' perceptions of the usefulness of ICTs for business education classroom instructions in Nigerian tertiary institutions. Asia Pacific Educ. Rev. 2018, 19, 337-352, doi:10.1007/s12564-018-9525-x.

20. Şad, S.N. An attitude scale for smartboard use in education: Validity and reliability studies. Comput. Educ. 2012, 58, 900-907, doi:10.1016/j.compedu.2011.10.017.

21. Bagozzi, RP; Warshaw, P.R. Trying to Consume. J. Consum. Res. 1990, 17, 127, doi:10.1086/208543.

22. Abdullah Moafa, F.; Ahmad, K.; Al-Rahmi, W.M.; Yahaya, N.; Bin Kamin, Y.; Alamri, M.M. Develop a model to measure the ethical effects of students through social media use. IEEE Access 2018, 6, 56685-56699, doi:10.1109/ACCESS.2018.2866525.

23. Robson, P.J.A.; Kickul, J.; Carsrud, A.L. Government Bureaucracy, Transactional Impediments, and Entrepreneurial Intentions. Int. Small Bus. J. 2009, 27, 626-645, doi:10.1177/0266242609338752.

24. Ismail, A.; Hassan, R.; Abubakar, A.; Hussin, H.; Mat Hanafiah, MA; Asary, L.H. The development of tvet educator competencies for quality Educator. J. Tech. Educ. Train. 2018, 10, 38-48.

25. Chakroun, B. National Qualifications Framework and TVET teacher competence frameworks: A neglected dimension of qualifications reforms? Eur. J. Educ. 2019, 370-388, doi:10.1111/ejed.12359.

26. Lee, C.J.; Kim, C.M. An implementation study of a TPACK-based instructional design model in a technology integration course. Educ. Technol. Res. Dev. 2014, 62, 437-460, doi:10.1007/s11423-014-9335-8.

27. Chee Sean, L.; Hamisu, M.; Mohd Salleh, K. Determining the Elements of TVET Teachers Competency for Nigerian Higher Learning Institutions. J. Phys. Conf. Ser. 2018, 1049, 1-8, doi:10.1088/1742-6596/1049/1/012078.

28. Mulder, M.; Weigel, T.; Collins, K. The concept of competence in the development of vocational education and training in selected EU member states: A critical analysis. J. Vocat. Educ. Train. 2007, 59, 67-88, doi:10.1080/13636820601145630.

29. F National Policy on Education. J. Res. Comput. Educ. 1988, 20, 271-286, doi:10.1080/08886504.1988.10781841.

30. Andersson, P.; Köpsén, S. Continuing professional development of vocational teachers: Participation in a Swedish National Initiative. Empir. Res. Vocat. Educ. Train. 2015, 7, doi:10.1186/s40461-015-0019-3.

31. Arif, S.; Sidek, S. Application of halalan tayyiban in the standard reference for determining Malaysian halal food. Asian Soc. Sci. 2015, 11, 116-129, doi:10.5539/ass.v11n17p116.

32. Okoye, K.; Arrona-Palacios, A.; Camacho-Zuñiga, C.; Hammoud, N.; Nakamura, E.L.; Escamilla, J.; Hosseini, S. Impact of student's evaluation of teaching: a text analysis of the teachers' qualities by gender. Int. J. Educ. Technol. High. Educ. 2020, 17, doi:10.1186/s41239-020-00224-z.

33. Salleh, KM; Khalid, N.H.; Sulaiman, N.L.; Mohamad, M.M.; Sean, L.C. Competency of Adult Learners in Learning: Application of the Iceberg Competency Model. Procedia - Soc. Behav. Sci. 2015, 204, 326-334, doi:10.1016/j.sbspro.2015.08.160.

34. Baturay, M.H.; Gökçearslan, Ş.; Şahin, Ş. Associations among teachers' attitudes towards computer-assisted education and TPACK competencies. Informatics Educ. 2017, 16, 1-23, doi:10.15388/infedu.2017.01.

35. Tondeur, J.; Van Braak, J.; Siddiq, F.; Scherer, R. Time for a new approach to prepare future teachers for educational technology use: Its meaning and measurement. Comput. Educ. 2016, 94, 134-150, doi:10.1016/j. compedu.2015.11.009.

36. Remigios, M. V. Journal of Sustainable Development in Africa. J. Sustain. Dev. Africa 2010, 12, $233-239$.

37. Afeti, G. Technical and vocational education and training for industrialization. Educ. Res. Dev. Counc. Press. 2009, 4, 205-234.

38. Afeti, G. Technical and vocational education and training for industrialization. 2009.

39. UNESCO The Flagship on Education for All and the Right to education for Persons with Disabilities: Towards Inclusion. 2004, $1-42$.

40. Wesolowski, D.G.\& HR Assessment of critical vocational behaviours career development for exceptional individuals. 2015, 5, 25-37, doi:10.1016/j. compedu.2018.03.002. 
41. Mohamad, M.M.; Yee, M.H.; Tee, TK; Ibrahim Mukhtar, M.; Ahmad, A. Teachers' pedagogical reasoning and action in technical and vocational education. J. Tech. Educ. Train. 2019, 11, 15-21, doi:10.30880/jtet.2019.11.03.003.

42. Al-Rahmi, W.M.; Yahaya, N.; Alamri, M.M.; Aljarboa, N.A.; Kamin, Y. Bin; Moafa, F.A. A model of factors affecting cyberbullying behaviors among university students. IEEE Access 2019, 7, 2978-2985, doi:10.1109/ACCESS.2018.2881292.

43. Markauskaite, L. Exploring the structure of trainee teachers' ICT literacy: The main components of, and relationships between, general cognitive and technical capabilities. Educ. Technol. Res. Dev. 2007, 55, 547-572, doi:10.1007/s11423-007-9043-8.

44. Kristiawan, M. A Model for Upgrading Teachers' Competence on Operating Computer as Assistant of Instruction A Model for Upgrading Teachers Competence on Operating Computer as Assistant of Instruction. Glob. J. HUMAN-SOCIAL Sci. G Linguist. Educ. 2017.

45. Malik, S.; Rohendi, D.; Widiaty, I. Technological Pedagogical Content Knowledge (TPACK) with Information and Communication Technology (ICT) Integration: A Literature Review. 2019, 299, 498-503, doi:10.2991/ictvet-18.2019.114.

46. Wang, W.; Schmidt-Crawford, D.; Jin, Y. Preservice Teachers' TPACK Development: A Review of Literature. J. Digit. Learn. Teach. Educ. 2018, 34, 234-258, doi:10.1080/21532974.2018.1498039.

47. Hulya, G.; Ay en, K. A SHORT REVIEW of TPACK for TEACHER EDUCATION. Educ. Res. Rev. 2015, 10, 777-789, doi:10.5897/err2014.1982.

48. Scherer, R.; Tondeur, J.; Siddiq, F. On the quest for validity: Testing the factor structure and measurement invariance of the technology-dimensions in the Technological, Pedagogical, and Content Knowledge (TPACK) model. Comput. Educ. 2017, 112, 1-17, doi:10.1016/j.compedu.2017.04.012.

49. Akturk, A.O.; Ozturk, H.S. Teachers' TPACK levels and students' self-efficacy as predictors of students' academic achievement. Int. J. Res. Educ. Sci. 2019, 5, 283-294.

50. Simon, S. \& Donovan, T. Non-Profit Life Stage Assessment, 2001.

51. Ingabire, Marie claire; Liu, Y.; Pesha, J.C.; Hardi, A. Factors Affecting Adoption of Artificial Insemination Technology by Small Dairy Farmers in Rwanda: A Case of Rwamagana District; 2018; Vol. 9;.

52. CRESWELL, J.W. RESEARCH DESIGN; 2017; Vol. 7; ISBN 9781412965569.

53. Ranjit Kumar RESEARCH METHODOLOGY A STEP-BY-STEP GUIDE FOR BEGINNERS; Ranjit Kumar, Ed.; 3rd ed.; 2014; ISBN 9781849203005.

54. Abba, SI; Elkiran, G. Effluent prediction of chemical oxygen demand from the wastewater treatment plant using artificial neural network application. Procedia Comput. Sci. 2017, 120, 156-163, doi:10.1016/j. procs.2017.11.223.

55. Hamed, M.M.; Khalafallah, M.G.; Hassanien, E.A. Prediction of wastewater treatment plant performance using artificial neural networks. Environ. Model. Software. 2004, 19, 919-928, doi:10.1016/j.envsoft.2003.10.005.

56. Abba, SI; Nourani, V.; Elkiran, G. Multi-parametric modeling of water treatment plant using AI-based non-linear ensemble. J. Water Supply Res. Technol. 2019, 68, 547-561.

57. Hamisu, M.A.; Salleh, KM; Sean, L.C.; Adamu, BY; Gambo, K. Proposed Competency Model for Technical and Vocational Education and Training (TVET) Lecturers Teaching in Technical Colleges, Bauchi State in Perspective. Path Sci. 2017, 3, 5001-5009, doi:10.22178/pos.26-7.

58. Khademi, F.; Jamal, S.M.; Deshpande, N.; Londhe, S. Predicting strength of recycled aggregate concrete using Artificial Neu-

ral Network, Adaptive Neuro-Fuzzy Inference System and Multiple Linear Regression. Int. J. Sustain. Built Environ. 2016, 5, 355-369, DOI: 10.1016/j.ijsbe.2016.09.003.

59. Glowacki, E.M.; McGlone, M.S.; Bell, RA Targeting Type 2: Linguistic Agency Assignment in Diabetes Prevention Policy Messaging. J. Health Commun. 2016, 21, 457-468, doi:10.1080/10810730.2015.1095821.

60. Abba, SI; Hadi, S.J.; Abdullahi, J. River water modelling prediction using multi-linear regression, artificial neural network, and adaptive neuro-fuzzy inference system techniques. In Proceedings of the Procedia Computer Science; 2017; Vol. 120, pp. 75-82.

61. Goodwin, A.L. Who is in the Classroom Now? Teacher Preparation and the Education of Immigrant Children. Educ. Stud. 2017, 53, 433-449, doi:10.1080/00131946.2016.1261028.

62. Agyei, D.D.; Voogt, J. Developing technological pedagogical content knowledge in pre-service mathematics teachers through collaborative design. Australas. J. Educ. Technol. 2012, 28, 547-564, doi:10.14742/ajet.827.

63. Alazam, A.-O.; Bakar, AR; Hamzah, R.; Asmiran, S. Teachers' ICT Skills and ICT Integration in the Classroom: The Case of Vocational and Technical Teachers in Malaysia. Creat. Educ. 2012, 03, 70-76, doi:10.4236/ce.2012.38b016.

64. Daramola, FO; Yusuf, M.O.; Oyelekan, S. Information and Communication Technology Literacy among Student-Teachers in Universities in Nigeria. Malaysian Online J. Educ. Technol. 2015, 3, 13-22.

65. Lavasani, M.G.; Khandan, F. Cypriot Journal of Educational. Cypriot J. Educ. 2011, 2, 61-74.

66. Buntat, Y.; Saleh, N.M.; Musban, M.; Musta'amal@Jamal, A.H.; Saud, M.S.; Nor, F.M. Competency-Based Education: A Case of Akademi Binaan Malaysia. Procedia - Soc. Behaviour. Sci. 2013, 93, 1536-1540, DOI: 10.1016/j.sbspro.2013.10.078.

67. Gündoğdu, K.; Sİlman, F.; Ozan, C. A comparative study on perception of teachers on the use of computers. Int. Online J. Educ. Sci. 2011, 3, 113-137.

68. Adodo, S.O. A Predictive Study of Pre - Service Teachers' Gender, Self-Concept, Interest and Attitude Towards Interactive Computer Technology (ICTS) in Nigeria Universities Faculties of Education. 2012, 2, 145-151, doi:10.5901/jesr.2012v2n3p145.

69. Omar, M.K.; Zahar, F.N.; Rashid, A.M. Knowledge, skills, and attitudes as predictors in determining teachers' competency in Malaysian TVET institutions. University. J. Educ. Res. 2020, 8, 95-104, doi:10.13189/ujer.2020.081612. 
